\title{
The effectiveness of decompression as initial treatment for jaw cysts: A 10-year retrospective study
}

\author{
Saša Marin ${ }^{1}$, Barbara Kirnbauer ${ }^{2}$, Petra Rugani ${ }^{2}$, Alexandra Mellacher ${ }^{2}$, Michael Payer ${ }^{3}$, Norbert Jakse ${ }^{4}$ \\ ${ }^{1}$ Doctor of Dental Medicine, Oral surgery specialist, Department of Oral Surgery, Faculty of Medicine, University of Banja Luka \\ ${ }^{2}$ Doctor of Dental Medicine, Division of Oral Surgery and Orthodontics, Department of Dental Medicine and Oral Health, Medi- \\ cal University of Graz \\ ${ }^{3}$ Associate Professor, Division of Oral Surgery and Orthodontics, Department of Dental Medicine and Oral Health, Medical \\ University of Graz \\ ${ }^{4}$ Full Professor and Head, Division of Oral Surgery and Orthodontics, Department of Dental Medicine and Oral Health, Medical \\ University of Graz
}

Correspondence:

Division of Oral Surgery and Orthodontics

Department of Dental Medicine and Oral Health

Medical University of Graz

Billrothgasse 4, A-8010 Graz, Austria

sasa.marin@med.unibl.org

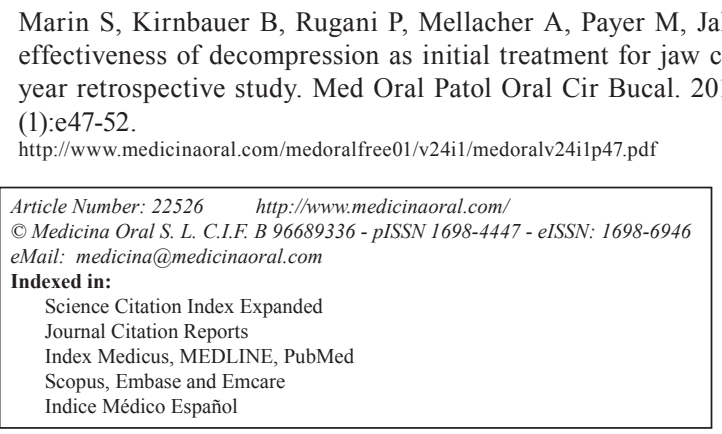

\begin{abstract}
Background: Decompression is an approved alternative to cystectomy in the treatment of jaw cysts. This study aimed to evaluate its effectiveness as an initial procedure, as well as factors with potential to influence outcome. Material and Methods: the frequency of decompression was analysed, whether completed in one session or followed by enucleation at the Division of Oral Surgery and Orthodontics, Department of Dental Medicine and Oral Health, Medical University of Graz, from 2005 to 2015. Further analysis focussed on factors potentially influencing outcome: cyst location, histopathology, means of preserving the cyst opening, cyst size, patient age.

Results: In all, 53 patients with 55 jaw cysts (mean age of 35.1) were treated by initial decompression in the ten-year period. In the majority of cases, histopathological analysis revealed a follicular cyst $(43.6 \%)$, followed by odontogenic keratocysts $(23.7 \%)$, radicular cysts $(21.8 \%)$, residual cysts $(7.3 \%)$ and nasopalatine cysts $(3.6 \%)$ Treatment was completed with a single decompression in $45.5 \%$ of the cases. Among those, $72.0 \%$ were follicular cysts and $8.0 \%$ odontogenic keratocysts. Subsequent enucleation was needed in $54.5 \%$ of all cases, with a majority in the keratocystic group (36.7\%). Histological findings, means of keeping the cyst open, and patient age were found to influence the effectiveness of decompression.

Conclusions: Decompression could be performed as a procedure completed in one session or combined with subsequent enucleation, mainly dependent on histopathological findings. Subsequent enucleation of odontogenic keratocysts is highly recommended.
\end{abstract}

Key words: Jaw cysts, decompression, enucleation, histopathology, obturator. 


\section{Introduction}

Cystic lesions occur more frequently in the upper and lower jaws than in other bones of the human body, mainly due to the presence of cells that are remnants of the embryonal neuroectoderm. One further explanation is that the embryonic teeth are located in the jaw bones. Triggers are either inflammatory stimuli or developmental disorders (1). Because they are usually slow growing and asymptomatic, cysts may grow very large, displacing and even damaging surrounding structures, with subsequent infection, root resorption, nerve injuries or bone fractures $(2,3)$.

Treatments range from single decompression, marsupialization, enucleation and bone resection to a combination of these approaches $(4,5)$. While there is no consensus on optimal treatment, complications and further morbidity are to be avoided, particularly with large cysts.

Decompression as initial procedure is a common conservative approach requiring preparation and preservation of a cyst opening. The aim is to decrease intracystic pressure by constant drainage, so allowing new centripetal bone growth from the bony cyst walls (6). The cyst opening can be preserved with simple iodoform gauze packing, a custom-made obturator, bracket and chain on involved impacted teeth, and drains $(7,8)$.

The main advantages of decompression are that it spares tissue, minimizes the likelihood of damage to adjacent structures, and avoids the cost of hospitalization $(9,10)$. Complications have been reported more frequently when enucleation was performed as a single procedure for extensive jaw cysts. According to the literature, the prevalence of permanent sensory disturbance ranges from $2.0-18.0 \%$, of transient hypoesthesia from 8.0$35.0 \%$, and of incomplete ossification from $12.0-40.0 \%$ (11-15).

Disadvantages of decompression include the duration of treatment, discomfort, and reliance on patient compliance. Further, remnants of the epithelial lining can lead to cyst recurrence requiring further surgical treatment $(16,17)$.

Some authors have suggested subsequent enucleation for aggressive cysts with a high relapse rate, and when the outcome of decompression is unsatisfactory $(18,19)$. This retrospective study aimed to evaluate the effectiveness of decompression for treatment of jaw cysts with consideration of possible outcome-influencing factors including patient age, cyst location and size, histopathology, and means of preserving the cyst opening.

\section{Material and Methods}

After approval of the study by the local ethics committee, data were collected and analysed from patients who had undergone decompression at the Division of Oral Surgery and Orthodontics, Department of Dental Medi- cine and Oral Health, Medical University of Graz, from 2005 to 2015.

The inclusion criteria for the study were cyst in the upper or lower jaw treated with decompression and complete medical records.

The exclusion criteria were cyst in the upper or lower jaw treated initially with enucleation or resection, soft tissue cysts, and incomplete medical records.

The following data were collected and analysed: frequency of decompression and decompression followed by enucleation, patient's age and gender, location and size of the cyst, histopathological findings, means of preserving the cyst opening.

Histopathology reports were obtained from the Institute of Pathology of the Medical University of Graz.

After surgical decompression, the cyst was kept open with iodoform gauze for the first few postoperative days. Thereafter, besides continued gauze packing, obturators, brackets with chains, and drains were used. Patients were advised to follow all postsurgical instructions scrupulously, rinsing the cyst opening twice a day with $0.9 \% \mathrm{NaCl}$ solution using a syringe, and cleaning dental devices mechanically with a toothbrush or swabs. For the first 2 days, postoperative care included cryotherapy with cold packs and for pain management, dexibuprofen $200 \mathrm{mg}$ for children and $400 \mathrm{mg}$ for adults (Seractil ${ }^{\circledR} 200$ or $400 \mathrm{mg}$, Gebro Pharma, Austria) 3 times a day. Routine follow-up included clinical and radiological studies at least every three months. Additional appointments were arranged depending on individual needs and compliance. Digital panoramic x-rays were taken with the Orthophos XG plus DS (Sirona Dental Systems GmbH, Bensheim, Germany) with $60-70 \mathrm{kVp}$ and $14-17 \mathrm{~mA}$.

Those patients with insufficient cyst shrinkage after decompression later underwent enucleation (Figs. 1,2).

-Statistical analysis

Data were presented with descriptive statistics. The statistical analyses were performed with SPSS software (IBM SPSS statistics 24.0, IBM Corporation, New York, United States) at a 5\% significance level. The chisquare test and Student's t-test were applied to quantitative and continuous variables.

\section{Results}

There were 53 patients (55 cysts) in the ten-year study period with a mean age of 35.1 years; 39 were male (73.6\%) and 14 female (26.4\%) (Table 1). Cysts were more common in the mandible (38 cysts) than in the maxilla (17 cysts). Mandibular cysts were most often found in the posterior region (molar-retromolar (34.2\%) followed by retromolar (23.7\%)), while maxillary cysts were most common in the frontal region (35.2\%) (Table 2). Follicular cysts were most frequent $(43.6 \%)$, followed by odontogenic keratocysts (23.7\%), radicular 

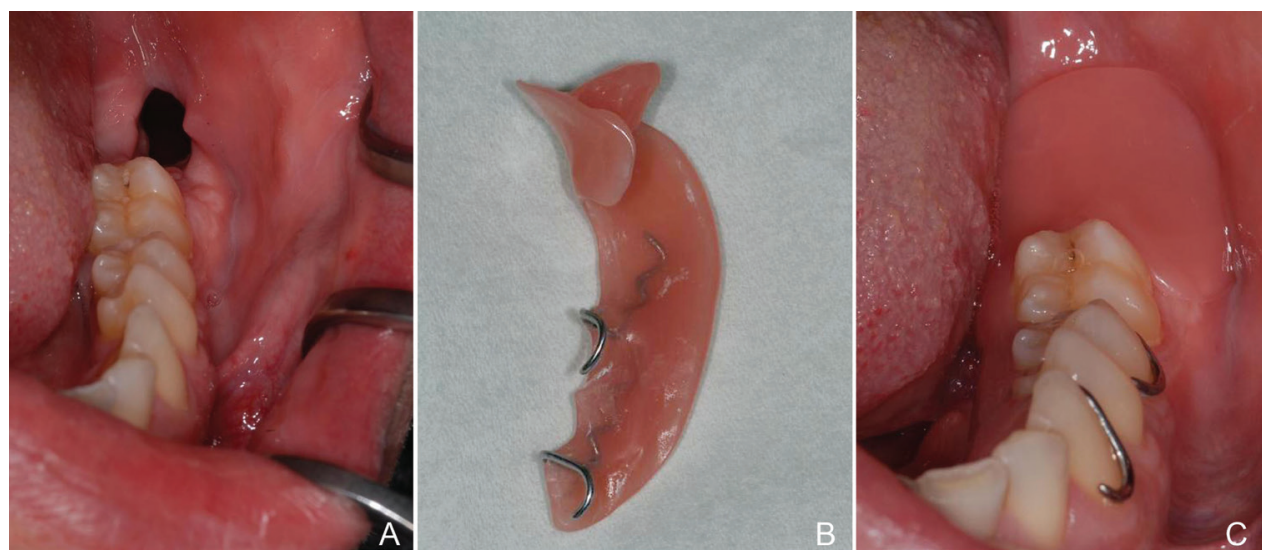

Fig. 1. (A) the cyst opening 7 days after decompression; (B) customized obturator; (C) applied customized obturator.
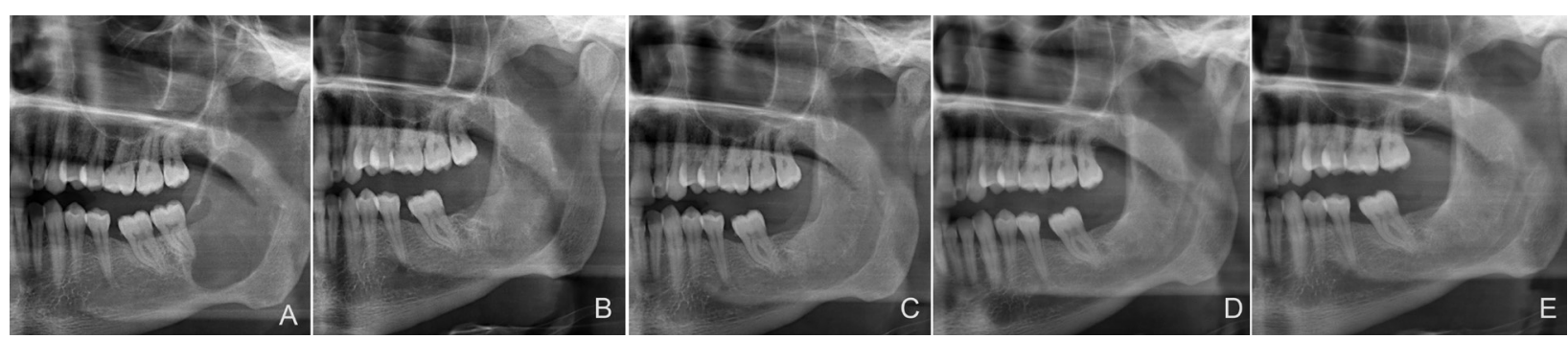

Fig. 2. (A) panoramic radiograph of odontogenic keratocyst before decompression; (B) panoramic radiograph 1 year after decompression and before subsequent enucleation; (C) panoramic radiograph 1 year after subsequent enucleation; (D) panoramic radiograph obtained 2 years after subsequent enucleation; (E) panoramic radiograph 5 years after subsequent enucleation.

Table 1. Descriptive patient data.

\begin{tabular}{|l|c|c|c|c|c|}
\hline Sex & $\begin{array}{c}\text { Cysts } \\
\mathrm{n}(\%)\end{array}$ & $\begin{array}{c}\text { Patients } \\
\mathrm{n}(\%)\end{array}$ & Mean age & SD & $\boldsymbol{p}$ \\
\cline { 1 - 4 } Male & $40(72.7)$ & $39(73.6)$ & 38.9 & 19.7 & \multirow{2}{*}{$p=0.013$} \\
\cline { 1 - 4 } Female & $15(27.3)$ & $14(26.4)$ & 24.9 & 18.4 & \\
\cline { 1 - 4 } Total & $55(100.0)$ & $53(100.0)$ & 35.1 & 20.2 & \\
\hline
\end{tabular}

Table 2. Distribution of the cysts and surgical procedures by jaw location.

\begin{tabular}{|l|c|c|c|c|c|}
\hline Location & $\begin{array}{c}\text { Maxilla } \\
\mathrm{n}(\%)\end{array}$ & $\begin{array}{c}\text { Mandible } \\
\mathrm{n}(\%)\end{array}$ & $\begin{array}{c}\text { Total } \\
\mathrm{n}(\%)\end{array}$ & $\begin{array}{c}\text { Decompression } \\
\mathrm{n}(\%)\end{array}$ & $\begin{array}{c}\text { Decompression } \\
\text { and enucleation } \\
\mathrm{n}(\%)\end{array}$ \\
\hline Frontal & $6(35.2)$ & $4(10.5)$ & $10(18.2)$ & $9(36)$ & $1(3.3)$ \\
\hline Frontal-premolar & $4(23.5)$ & $2(5.3)$ & $6(10.9)$ & $2(8)$ & $4(13.4)$ \\
\hline Frontal-premolar-molar & $2(11.8)$ & $0(0.0)$ & $2(3.6)$ & $1(4)$ & $2(6.7)$ \\
\hline Premolar & $2(11,8)$ & $1(2.6)$ & $3(5.5)$ & $2(8)$ & $0(0.0)$ \\
\hline Premolar-molar & $1(5.9)$ & $2(5.3)$ & $3(5.5)$ & $2(8)$ & $1(3.3)$ \\
\hline Premolar-molar-retromolar & $1(5.9)$ & $0(0.0)$ & $1(1.8)$ & $0(0)$ & $1(3.3)$ \\
\hline Molar & $1(5.9)$ & $7(18.4)$ & $8(14.5)$ & $3(12)$ & $5(16.7)$ \\
\hline Molar-retromolar & $0(0.0)$ & $13(34.2)$ & $13(23.6)$ & $3(12)$ & $10(33.3)$ \\
\hline Retromolar & $0(0.0)$ & $9(23.7)$ & $9(16.4)$ & $3(12)$ & $6(20.0)$ \\
\hline Total & $17(100.0)$ & $38(100.0)$ & $55(100.0)$ & $25(100)$ & $30(100.0)$ \\
\hline
\end{tabular}


cysts $(21.8 \%)$, residual cysts $(7.3 \%)$ and nasopalatine cyst (3.6\%). Most commonly, an obturator was used to keep the cyst open (54.5\%), followed by bracket with chain $(25.5 \%)$, iodoform gauze packing (14.5\%), and drain (5.5\%) (Table 3).

\section{Discussion}

This retrospective study focused on the evaluation of the effectiveness of decompression for jaw cyst treatment over a ten-year period and the influence of different factors thereon. The main limitations of this study

Table 3. Relation between different factors and types of the surgical procedures.

\begin{tabular}{|c|c|c|c|c|}
\hline $\begin{array}{l}\text { Factors/ } \\
\text { subcategory }\end{array}$ & $\begin{array}{c}\text { Decompression } \\
\mathrm{n}(\%)\end{array}$ & $\begin{array}{c}\text { Decompression } \\
\text { and enucleation } \\
n(\%)\end{array}$ & $\begin{array}{l}\text { Total } \\
\text { n }(\%)\end{array}$ & $p$ \\
\hline All & $25(45.5)$ & $30(54.5)$ & $55(100.0)$ & \\
\hline \multicolumn{5}{|l|}{ Histopathology } \\
\hline Follicular cyst & $18(72.0)$ & $6(20.0)$ & $24(43.6)$ & \multirow{5}{*}{$p=0.003$} \\
\hline Odontogenic keratocyst & $2(8.0)$ & $11(36.7)$ & $13(23.7)$ & \\
\hline Nasopalatine cyst & $1(4.0)$ & $1(3.3)$ & $2(3.6)$ & \\
\hline Radicular & $3(12.0)$ & $9(30,0)$ & $12(21,8)$ & \\
\hline Residual cyst & $1(4.0)$ & $3(10,0)$ & $4(7,3)$ & \\
\hline \multicolumn{5}{|l|}{ Means } \\
\hline Bracket and chain & $11(44.0)$ & $3(10.0)$ & $14(25.5)$ & \multirow[t]{4}{*}{$p=0.020$} \\
\hline Obturator & $11(44.0)$ & $19(63.3)$ & $30(54.5)$ & \\
\hline Drain & $0(0)$ & $3(10.0)$ & $3(5.5)$ & \\
\hline Iodoform gauze packing & $3(12.0)$ & $5(16.7)$ & $8(14.5)$ & \\
\hline \multicolumn{5}{|l|}{ Cyst diameter (mm) } \\
\hline $0-40$ & $18(72.0)$ & $17(56.6)$ & $35(63.6)$ & \multirow[t]{3}{*}{$p=0.399$} \\
\hline $40-80$ & $5(20,0)$ & $11(36.7)$ & $16(29.1)$ & \\
\hline $80-120$ & $2(8.0)$ & $2(6.7)$ & $4(7.3)$ & \\
\hline \multicolumn{5}{|l|}{ Patient age (years) } \\
\hline $0-30$ & $14(56.0)$ & $8(26.7)$ & $22(40.0)$ & \multirow[t]{3}{*}{$p=0.025$} \\
\hline $30-60$ & $8(32.0)$ & $18(60.0)$ & $26(47.3)$ & \\
\hline$>60$ & $3(12.0)$ & $4(13.3)$ & $7(12.7)$ & \\
\hline
\end{tabular}

A single decompression completed treatment in $45.5 \%$ of cases, mostly in the frontal region of the jaws and in patients under 30 years $(56.0 \%)$. Among these patients, follicular cysts were most frequent $(72.2 \%)$ and the most commonly used devices were brackets with chains (44.0\%) (Table 3).

Subsequent enucleation was needed in $54.5 \%$ of the cases, mostly in the posterior region. Patients were usually 30-60 years old (60\%) and odontogenic keratocysts $(36.7 \%)$ were most common. An obturator was often used after decompression followed by enucleation $(63.3 \%)$ (Table 3).

The effectiveness of decompression was found to correlate with histopathology, the means of keeping the cyst open, and patients' age ( $p=0.003, p=0.020$ and $p=0,025)$. More detailed information is presented in Table 3.

The cyst's diameter was not found to have an influence on the effectiveness of the procedure $(p=0.399)$ (Table 3). were that it was retrospective and that medical data were not always complete.

The study included 53 patients with a mean age of 35.1 years and 55 cystic lesions treated initially with decompression. In accordance with the literature, the most frequent cystic lesions occurred in anterior maxilla in male patients (20-22), though there were more cysts overall in the mandible than the maxilla. The reason for the higher frequency of the cysts in lower jaw could be the use of enucleation as the initial treatment for cystic lesions in maxilla, while this study focused on jaw cysts initially treated with decompression.

Similarly, histopathologically, follicular cysts and odontogenic keratocysts were most frequent (43.6\% and $23.7 \%$, respectively). The literature indicates that radicular cysts are the most frequent cysts in the jaws (23). Radicular cysts are smaller and are initially treated with enucleation. Only large radicular cysts are treated with decompression when enucleation could damage 
surrounding structures, or in the case of geriatric and high-risk patients. The frequencies of residual cysts and nasopalatine cysts of $7.3 \%$ and $3.6 \%$, respectively, are in line with the literature averages of $4.2-13.7 \%$ and $2.2-4.0 \%(20,22)$. Histopathological findings showed that the cyst type influences the surgical approach ( $p=0.003$ ), with decompression followed by enucleation applied mostly for odontogenic keratocysts. As a single procedure, decompression was most frequently used for follicular cysts $(72 \%)$, but only for $8 \%$ of odontogenic keratocysts. Some authors have advocated decompression for odontogenic keratocysts (24), although surgeons often prefer decompression followed by enucleation for these aggressive cysts that are highly prone to recurrence (18).

Various means of preserving the cyst opening have been described in the literature $(19,24)$, but there is little information on their comparative effectiveness. In this study, a statistically significant difference was found in the use of means of preserving the cyst opening and the frequency of decompression or decompression followed by enucleation $(p=0.020)$. Decompression showed more success when brackets and chains were used rather than other devices. The reason could that brackets with chains are mostly used for follicular cysts. Although obturators can be custom made, it may not be easy to create a precise obturator due to the position of the opening in the mouth, tissue remodelling and imprecise impressions of the inner lumen. Iodoform gauze packing and drain tubes might be used less often due to the surgeon's preference and the need for extensive after-care. Some patients have difficulty keeping appointments to have their iodoform gauze changed, while others may be over-challenged with keeping a drain clean (11).

The management of various sizes of the cysts continues to be discussed. Jeong et al. concluded that the initial size of the cyst influences the outcome of decompression (25), while Anavi et al. did not find any influence of the initial cyst's size on the outcome of decompression, which is in accordance with our results ( $p=0.399$ ). However, decompression followed by enucleation was used more often when the cyst's diameter exceeded 40 $\mathrm{mm}$. Jeong et al. made three-dimensional cyst measurements while Anavi et al. made cyst measurements on panoramic records $(11,25)$. A shortcoming of this study could be measuring the largest cyst diameter on panoramic records and not taking into account the buccallingual dimensions of the cystic lesions.

The relationship between patient age and the reduction rate of the cyst's size after treatment is still unclear. Some studies have found patient age to be an important factor in the cyst's healing process $(26,27)$, while others have failed to find a correlation $(28,29)$. In this study, patient age seemed to have an effect on the surgical treatment chosen $(p=0.025)$. Decompression was more successful in patients under 30 years of age than in older patients, which could be explained by the higher occurrence of follicular cysts in younger patients. Follicular cysts are not as aggressive as odontogenic keratocysts, which is why the process is likely to succeed when decompression is the chosen treatment.

\section{Conclusions}

Decompression is mainly performed to avoid morbidity. It can be performed as a single complete procedure or combined with subsequent enucleation, mainly depending on histopathological findings. Enucleation after decompression is highly recommended for odontogenic keratocysts.

\section{References}

1. Slootweg PJ. Lesions of the jaws. Histopathology. 2009;54:401-18. 2. Manor E, Kachko L, Puterman MB, Szabo G, Bodner L. Cystic lesions of the jaws - a clinicopathological study of 322 cases and review of the literature. Int J Med Sci. 2012;9:20-6.

3. Mark HS, Song IS, Seo BM, Lee JH, Kim MJ. The effectiveness of decompression for patients with dentigerous cysts, keratocystic odontogenic tumors and unicystic ameloblastoma. J Korean Assoc Oral Maxillofac Surg. 2014;40:260-5.

4. Mendes RA, Carvalho JF and van der Waal I. Characterization and management of the keratocystic nodontogenic tumor in relation to its histopathological and biological features. Oral Oncol. 2010;46:219-25.

5. Wakolbinger R, Beck-Mannagetta J. Long-term results after treatment of extensive odontogenic cysts of the jaws: a review. Clin Oral Investig. 2015;20:15-22.

6. Schlieve T, Miloro M, Kolokythas A. Does decompression of odontogenic cysts and cystlike lesions change the histologic diagnosis?. J Oral Maxillofac Surg. 2014;72:1094-105.

7. Carter LM, Carr P, Wales CJ, Whitfield PH. Customised stents for marsupialisation of jaw cysts, $\mathrm{Br} \mathrm{J}$ Oral Maxillofac Surg. 2007;45:429-31.

8. Rehman KU, Opie N, Parmar S, Jeynes P. The oral grommet. Br J Oral Maxillofac Surg. 2008;46:692-3.

9. Maurette PE, Jorge J, de Moraes M. Conservative treatment protocol of odontogenic keratocyst: a preliminary study. J Oral Maxillofac Surg. 2006;64:379-83.

10. Litvin M, Caprice D, Infranco L. Dentigerous cyst of the maxilla with impacted tooth displaced into orbital rim and floor. Ear Nose Throat J. 2008;87:160-2.

11. Anavi Y, Gal G, Miron H, Calderon S, Allon DM. Decompression of odontogenic cystic lesions: clinical long-term study of 73 cases. Oral Surg Oral Med Oral Pathol Oral Radiol Endod. 2011;112:164-9. 12. Van Doorn ME. Enucleation and primary closure of jawcysts. Int J Oral Surg. 1972;1:17-25.

13. Richter M, Laurent F, Chausse JM. Homologous cancellous bone grafts for large jaw defects caused by bone cysts. J Oral Maxillofac Surg. 1986;44:447-53.

14. Stoelinga PJ. Long-term follow-up on keratocysts treated according to a defined protocol. Int J Oral Maxillofac Surg. 2001;30:14-25. 15. Schultze-Mosgau S, Reich RH. Assessment of inferior alveolar and lingual nerve disturbances after dentoalveolar surgery, and of recovery of sensitivity. Int J Oral Maxillofac Surg. 1993;22:214-17. 16. Habibi A, Saghravanian N, Habibi M, Mellati E, Habibi M. Keratocystic odontogenic tumor: a 10-year retrospective study of 83 cases in an Iranian population. J Oral Sci. 2007;49:229-35.

17. Berdén J, Koch G, Ullbro C. Case series: treatment of large dentigerous cysts in children. Eur Arch Paediatr Dent. 2010;11:140-5.

18. Enislidis G, Fock N, Sulzbacher I, Ewers R. Conservative treatment of large cystic lesions of the mandible: a prospective study of 
the effect of decompression. Br J Oral Maxillofac Surg. 2004;42:54650 . .

19. Pogrel AN. Treatment of keratocysts: the case for decompression and marsupialization. J Oral Maxillofac Surg. 2005;63:1667-73.

20. Tekkesin MS, Olgac V, Aksakalli N, Alatli C. Odontogenic and nonodontogenic cysts in Istanbul: analysis of 5088 cases. Head Neck. 2012;34:852-5.

21. Johnson NR, Savage NW, Kazoullis S, Batstone MD. A prospective epidemiological study for odontogenic and nonodontogenic lesions of the maxilla and mandible in Queensland. Oral Surg Oral Med Oral Pathol Oral Radiol. 2013;115:515-22.

22. Koivisto T, Bowles WR, Rohrer M. Frequency and Distribution of Radiolucent Jaw Lesions: A Retrospective Analysis of 9,723 Cases. J Endod. 2012;38:729-32.

23. Demirkol M, Ege B, Yanik S, Aras MH, Ay S. Clinicopathological study of jaw cysts in southeast region of Turkey. Eur J Dent. 2014;8:107-11.

24. Pogrel MA, Jordan RC. Marsupialization as a definitive treatment for the odontogenic keratocyst. J Oral Maxillofac Surg. 2004;62:6515

25. Jeong HG, Hwang JJ, Lee SH, Nam W. Effect of decompression for patients with various jaw cysts based on three-dimensional computed tomography analysis. Oral Surg Oral Med Oral Pathol Oral Radiol. 2017;123:445-52.

26. Park HS, Song IS, Seo BM, Lee JH, Kim MJ. The effectiveness of decompression for patients with dentigerous cysts, keratocystic odontogenic tumors, and unicystic ameloblastoma. J Korean Assoc Oral Maxillofac Surg. 2014;40:260-5.

27. Gao L, Wang XL, Li SM, Liu CY, Chen C, Li JW et al. Decompression as a treatment for odontogenic cystic lesions of the jaw. $\mathrm{J}$ Oral Maxillofac Surg. 2014;72:327-33.

28. Abdullah WA: Surgical treatment of keratocystic odontogenic tumour: A review article. Saudi Dent J. 2011;23:61-5.

29. Lizio G, Sterrantino AF, Ragazzini S, Marchetti C. Volume reduction of cystic lesions after surgical decompression: a computerised three-dimensional computed tomographic evaluation. Clin Oral Investig. 2013;17:1701-8.

\section{Ethics statement}

The study was approved by the Ethics Committee of the Medical University Graz, 27-523 ex 14/15.

\section{Acknowledgements}

We thank D.I. Irene Mischak for statistical analysis and Eugenia Lamont from the Section for Surgical Research, Medical University of Graz, for critical revision of the article.

\section{Conflict of interest}

There is no conflict of interest in this study and it did not receive any specific grant from funding agencies in the public, commercial, or not-for-profit sectors.

Saša Marin and Barbara Kirnbauer have contributed equally to this work. 